RISMED 00072

\title{
Editorial
}

\section{Risk management: a practical approach}

In this issue of the International Journal of Risk and Safety in Medicine we publish a series of nine papers which were presented at a Conference entitled "Risk Management: a Practical Approach", held in London on January 22nd 1991. The Symposium was organized by the Medical Defence Union, which has in the recent past devoted increasing effort to developing in the United Kingdom an approach to risk management in health care similar to that which has grown up in the United States of America. The papers were initially intended primarily for an audience of British physicians, but their message is valid for any country and health profession which is striving towards the complementary ideals of risk management and of quality control in the field of health care.

The papers from the Conference have been edited for the Journal by Dr Garth Hill MB BS, D. Obst RCOG, Senior Undersecretary of the Medical Defence Union.

M.N.G. Dukes 